\title{
CONSUMERS ATTITUDES TOWARDS ENVIRONMENTAL STANDARDS IMPLEMENTATION IN BULGARIA
}

\section{Albena Kraeva Miteva ${ }^{1}$, Hristina Harizanonva Bartos ${ }^{2}$}

\begin{abstract}
Globally, business organization units and government bodies are becoming much more aware of the need for environmental management, socially responsible behaviour, sustainable growth and development. In Bulgarian economy mentioned processes have been initiated within the several key sectors that are basically among the biggest polluters. To evaluate the issues concerning environmental standards the direction of the analysis is based on consumers' point of view. The main aim of the article is to analyse and evaluate attitudes of Bulgarian consumers toward environmental standards implementation in Bulgaria. The study is divided into 3 parts: 1) literature review concerning the need of implementation of environmental standards; 2) description of the used methodology and research toward implementation of ISO 14001 in Bulgaria by the opinion of the consumers; and 3) Analysis of the gathered information. On this basis, conclusions about the prospects for their development in the Bulgaria are drawn. The collected information and results are based on scientific project concerning the implementation of Standards for Social and Environmental Responsibility in Bulgaria (NI 1-4/2014).
\end{abstract}

Key words: Bulgaria, environmental standards, ISO 14000, EMAS, consumer behaviour.

JEL ${ }^{3}:$ Q50, Q56

\section{Introduction}

Conservation and management of environment is a problem following the development of human civilization but in recent decades has become a global one. The European Union supports the development of greener and more competitive economy, which strives to achieve the objectives of the concept of sustainable development. One important means for the introduction of standards for social and

1 Albena Kraeva Miteva, Ph.D., Full Professor, University of National and World Economy, Department of Economy of Natural Resources, Student Town, UNWE, 1700 Sofia, Bulgaria, Phone: +359 8888696 290, E-mail: albenakm@yahoo.com

2 Hristina Harizanonva Bartos, Ph.D., Associate Professor, University of National and World Economy, Department of Economy of Natural Resources, Student Town, UNWE, 1700 Sofia, Bulgaria, E-mail: h.harizanova@gmail.com

3 Article info: Original Article, Received: $4^{\text {th }}$ July 2019., Accepted: $14^{\text {th }}$ October 2019. 
environmental responsibility in Bulgaria as a condition for achieving environmental compatibility, social responsibility and economic viability, are the environmental management systems (EMS).

European Environmental Agency defines that the EMS provide effective implementation of the management plan and measures in accordance with the objectives and tasks of ecological politics (UNEP-IETC, 2000; IPCC, 2001; EC, 2006). The Law on Environmental Protection of Bulgaria defines the EMS as "that part of the general management system which includes organizational structure, planning activities, responsibilities, practices, procedures, processes and resources for developing, implementing, achieving, reviewing and maintaining environmental policy" (EPA, 2005).

A number of international organizations and governments develop and adopt international conventions, EU directives, a series of standards for quality management and environmental protection (Clausen et al., 2002). The standard is clear and concise, but fully sufficient to serve as a basis for development and implementation of EMS and allows achieving recognition of the implemented EMS. The main model of EMS described in the literature is those of environmental standards ISO 14001 and EMAS. ISO14000 series of standards are sufficient to serve as a basis for development and implementation of EMS. ISO 14001 specifies the standards for a company's EMS. At the same time the European Commission develops a "Scheme for environmental management and audit" (EMAS), which is similar to previous, but includes some additional requirements. Requirements of EMAS have been published as Regulation $1836 / 93$ in 1993. Participation in scheme is voluntary and open to public or private organizations operating in the EU or European Economic Community (EEC) Iceland, Liechtenstein and Norway. At same time requirements of ISO14001 are fully included in EMAS, which effectively makes certification of ISO14001 a basis for registration under EMAS (EC, 2009). In polish research regarding the business structures is pointed out that Systems (EMS) grow into the significant part of many strategic documents and usual requirement of environmentally aware societies, while a lot of organisations registered under the EMAS decreased. Meanwhile, the implementation of EMS linked to ISO 14001 is still very popular (Matuszak Flejszman et al., 2019). Sectorial analysis of the need of environmental certification stress that policy makers should develop legislative procedures which should be web based (Maijala, Pohjola, 2006).

Authors in different years (Ilieva, 1999; Peicheva et al., 2017; Peicheva, 2018; Dineva, 2019) stress on benefits of implementation of environmental and social standards as a tool for successful and sustainable business. In the research are reviled the needs for implementation of social audit and standards for social and environmental 
responsibility; good practice in the field of social audit and standards for social and environmental responsibility; legislation related to social audit and standards for social and environmental responsibility and audit. From environmental view, some authors stress that the related technological and economic advancement have increased significantly the pressure upon the planet and has resulted in expansion of humanity's ecological footprint (Iraldo et al., 2005; Ivanova et al., 2016).

Among the voluntary approaches to environmental protection applicable in Bulgaria are the National Scheme for Environmental Management and Auditing (NSUOSO). This scheme aims certification of organizations and their products under certain criteria and registering or marking them appropriately. NSUOSO was introduced in Bulgarian Legislation Regulation 761/2001/EC on the voluntary participation of organizations in the Environmental Management and Audit Scheme (EMAS) and ISO14001. The application of EMAS and ISO 14001 in Bulgaria complies with the European and Bulgarian eco-legislation (Miteva, 2017).

\section{Material and Methods}

The aim of the study is to analyse and evaluate the attitudes of Bulgarian consumers and businesses for ISO14001 and EMAS implementation in Bulgaria. The tasks associated with achieving the objectives are: 1) Analysis of the needs and attitudes of representatives of individuals for the use of environmental responsibility standards; and 2) Based on the aggregated and analysed information to formulate general conclusions about the prospects for their development in Bulgaria.

In attaining the objectives are used data from a scientific project concerning the implementation of Standards for Social and Environmental Responsibility in Bulgaria executed by a team from the University of National and World Economy. Within the project during the period 2015-2016 was conducted a survey on the attitudes to implement EMAS and ISO 14001 in Bulgaria For the purpose of the survey special questionnaire have been created. Assistance of the conduction of the study has been given by NGOs organizations, some researchers and partly government bodies. The electronic version of the questioner was distributed by connected with standardizations services in Bulgaria. Conducted interviews were regarding the difficulties encountered in their implementation and maintenance, and the benefits obtained from EMAS and ISO14000 implementation. The questions were generally seeking the answer of individuals' assessment of the importance of implementation of eco-standards in business organizations; the importance of the activities of the firms to not pollute the environment; assessing the importance of introduced EMAS or ISO14001; assessment of the benefits from implementation of eco-standards 
in business organizations; willingness of the business to implement practices for reduction of water, electricity and heat consumption, etc.

General socio-economic characteristic of the respondents is as follows: $71 \%$ of individual respondents are women. Respondents with higher education dominated by $80 \%$, students $15 \%$, while those with secondary education are only five percent. More than half of the participants (51\%) belong to the age group of up to 30 years, $19 \%$ were up to 40 years old, and $27 \%$ are people between 40 and 60 years of age. The interviewed people come from various economic sectors - the biggest part work in the construction industry and the sector providing advisory services, IT services and others (BIC, 2003).

Analyses of the study are based on 482 respondents from Bulgaria who provided their answers.

\section{Analysis of the needs and attitudes of representatives of individuals from implementation of standards for environmental responsibility in Bulgaria}

In Bulgaria exists a positive attitude towards implementation of eco-standards ISO 14000 and EMAS which is stood by the large number of interviewed people (93\%) expressing their firm opinion that the business organizations should certify their activity under one of these standards. I figure one is shown the main distribution of the importance of implementation of eco-standards in business organizations.

Figure 1. Distribution of individuals assessing the importance of implementation of eco-standards in business organizations

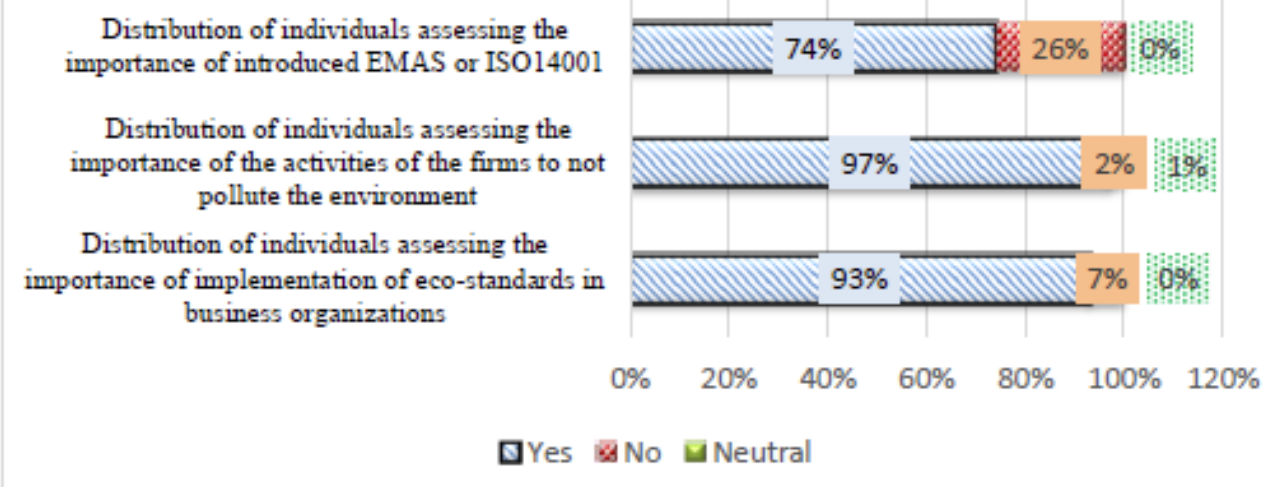

Source: Own findings, based on Research Project NI 1-4/2014 (UNWE, 2018). 
There is a positive attitude towards implementation of standards for environmentally responsible behaviour by firms from end users who are also workers in these companies. An evidence of this is the fact that $63 \%$ of respondents answered affirmatively when applying for a job were asked if they had been influenced positively by the fact that the company is certified according to ISO14001 or EMAS. Additionally, on the topic of creating jobs some Bulgarian researches connect the environmental certificates with green jobs creation and the impact on climate (Stoyanova, 2017; Sahin et al., 2019). Even more convincing are the respondents' answers to the question whether it is important for the individual respondents, these organizations to work in a way that does not pollute the environment, since $97 \%$ of respondents answered positively.

The increased environmental awareness, the grown problems with pollution are the cause the respondents to welcome ecologically responsible behaviour of companies and their purchases to be influenced of whether the desired goods or services are produced by a company applying ecological standards - nearly three-quarters of them $(74 \%)$ are positively influenced by the presence of introduced EMAS or ISO14001.

Individual respondents assess also realistically benefits from implementation of ecological standards. With equal share of $16 \%$ are ranked the factors "encouraging businesses to environmentally responsible behaviour" and "differentiation of socially responsible employers from socially irresponsible working in the grey economy." On the next place with a very close shares are listed the benefits "to strengthen control" and "increase the competitiveness of Bulgarian enterprises", "increase confidence in consumers". Less significance is allocated to answers oriented towards expansion of the customer base as well as their detention (Figure 2.).

Interesting is the fact that within the largest age group (19 to 25 years) participating in the survey, the benefit for companies to be certified under the standards for environmentally responsible behaviour is that this will encourage environmentally responsible behaviour of employers ( $16 \%$ of this age group), which is an expression of their strong citizen position. For the age groups ranging from 31 to 40 years, from 41 to 50 years and from 51 to 60 years, the benefit from certification of firms under the standards for environmental responsibility is the ability to distinguish socially responsible employers from socially irresponsible working in the informal economy and thus, to stimulate companies to have socially responsible behaviour. For the age group from 61 to 67 years the certification of firms under the standards for environmental responsibility will bring more control and will allow an increase of the competitiveness of Bulgarian companies. 
Figure 2. Distribution of individuals per assessed benefits from implementation of eco-standards in business organizations

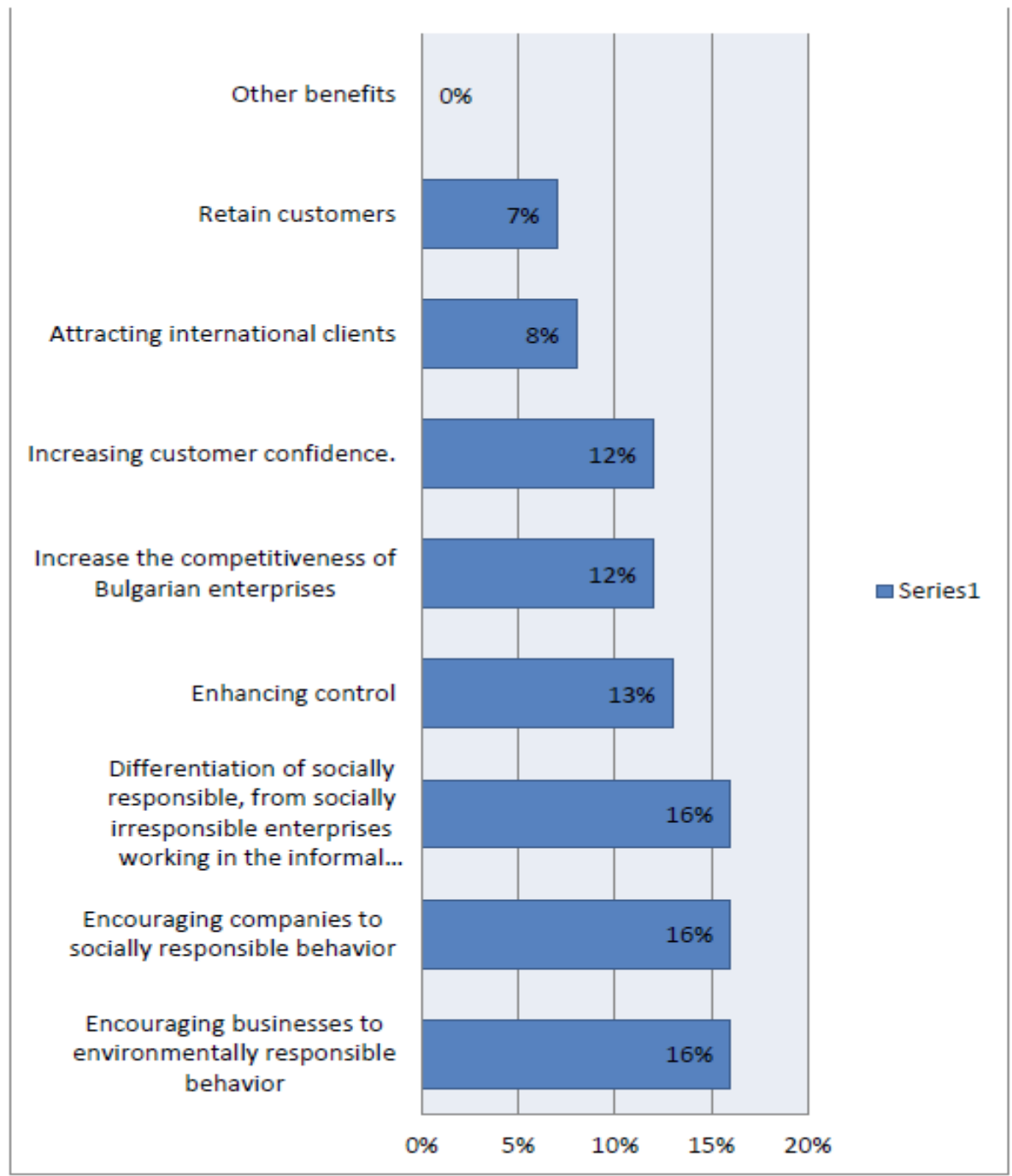

Source: Own findings, based on Research Project NI 1-4/2014 (UNWE, 2018).

The educational level of the respondents does not impact seriously the answers to the question about the benefits from the introduction of eco-standards. About $26 \%$ of respondents with secondary education state that the main benefit from certification of companies under the standards for environmental responsibility is the differentiation of socially responsible employers from socially irresponsible working in the informal economy, followed by "increased competitiveness" and "stimulate environmentally responsible behaviour". For respondents with secondary education who are currently 
students and respondents with higher education, the leading benefit from certification of firms under the standards for environmental responsibility is the stimulation of environmentally responsible behaviour. On the next place are pointed "distinguish socially responsible employers from socially irresponsible working in the informal economy", "strengthening of control", "improving consumer confidence".

The desire for a more efficient use of resources motivates consumers to be critical to the used technologies and to be active in their willingness organizations to implement practices which reduce consumption of electricity, water and heat. $35 \%$ of respondents want companies to be motivated to implement practices for reduction of electricity consumption, $30 \%$ favour reduction of water consumption, $27 \%$ support the idea the firms to adopt practices for more efficient use of heat (Figure 3). The age structure of respondents influence the opinion which practice is most important. The young generation believes that the use of energy-friendly technologies will be of most benefit, the population over 60 years believe that practices which reduce water use are most significant for nature preservation

Figure 3. Distribution of individuals per willingness to implement practices for reduction of water, electricity and heat consumption

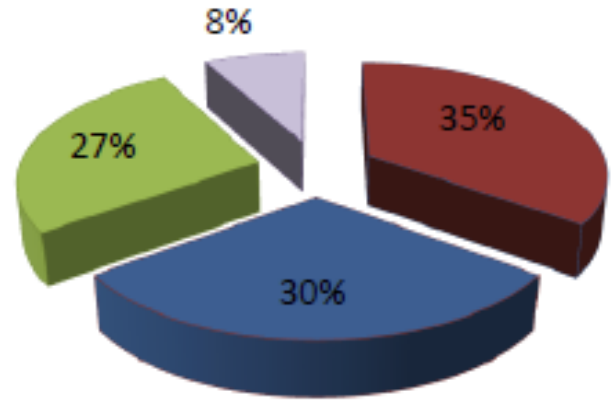

口electricity

water

heat

other

Source: Own findings, based on Research Project NI 1-4/2014 (UNWE, 2018).

No matter the educational structure of respondents, unanimously greatest importance is allocated to the practice related to the opportunities to reduce the use of electricity(over 35\%), followed by water resources reduction ( an average of 30\%), heat reduction $(29 \%)$ and others $(8 \%)$.

As major difficulties for expanding the supply of goods and services by companies certified under the eco-standards in Bulgaria, respondents indicate their higher price $138 \%$ / and the lack of a market for such goods (44\%). The factor cost is most significant among the youngest group of respondents (19-25 years) and for them this factor is weighted $47 \%$. As seen from the figure below, this percentage with the increase of age diminishes, reaching zero levels of influence in the age of retirement 
and after retirement. The lack of markets is with an average impact of $53 \%$, while for the respondents aged 61 to 67 years it is identified as a single stop-factor. The average rate of indifference is $26 \%$, having the highest level among the surveyed group aged above 67 years, where the percent is 67 , which is understandable with their already less pronounced active citizenship (Figure 4.).

Figure 4. Distribution of individuals defining the main restraints to increase the purchase of goods from companies implementing eco-standards

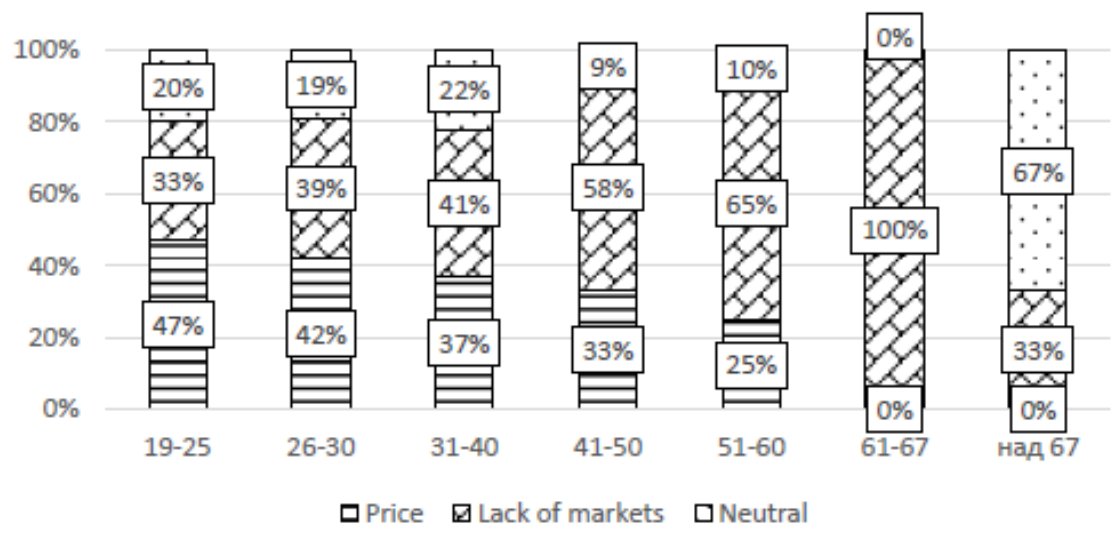

Source: Own findings, based on Research Project NI 1-4/2014 (UNWE, 2018).

The educational level did not significantly affect the choice of product or service from a company certified under EMAS or ISO14001. For respondents with secondary education the greatest restraint is the lack of a market for such products (about 67\% of this group). For respondents with secondary education who are students the largest barrier is the price (about 59\% of this group). For respondents with higher education the greatest limitation is the lack of a market for such products (about $46 \%$ of this group).

In Bulgaria there is a willingness of consumers to purchase goods and services offered by companies applying eco-standards. This is evidenced by the relatively high percentage of positive responses $/ 56 \%$ / of respondents whether in the near future they will focus their purchases on buying goods from companies which implement eco-standards. $100 \%$ of respondents aged 61 to 67 years provide a positive answer to this question. The age group from 41 to 50 years $(61 \%$ of them) declare that in the near future they will buy goods from companies implementing ISO 14000 or other environmental management system. Approximately the same percentage of answers $(60 \%)$ is given by the age group of 31 to 40 years and the age group from 26 to 30 years $(56 \%)$. Fluctuation shows the age group from 19 to 25 years because $55 \%$ of the participants in this group do not know whether they will focus their purchase power 
on buying goods from companies implementing ISO 14000 or other environmental management system. The need for serious awareness, educational and information campaigns on environmental, social and economic benefits from the application of environmental standards is proved by the large number of people $/ 42 \%$ / providing the answer "I do not know" to this question (Figure 5).

Figure 5. Distribution of individuals who declare their desire for a recent purchase of products and services from companies that have implemented eco-standards according to their educational level

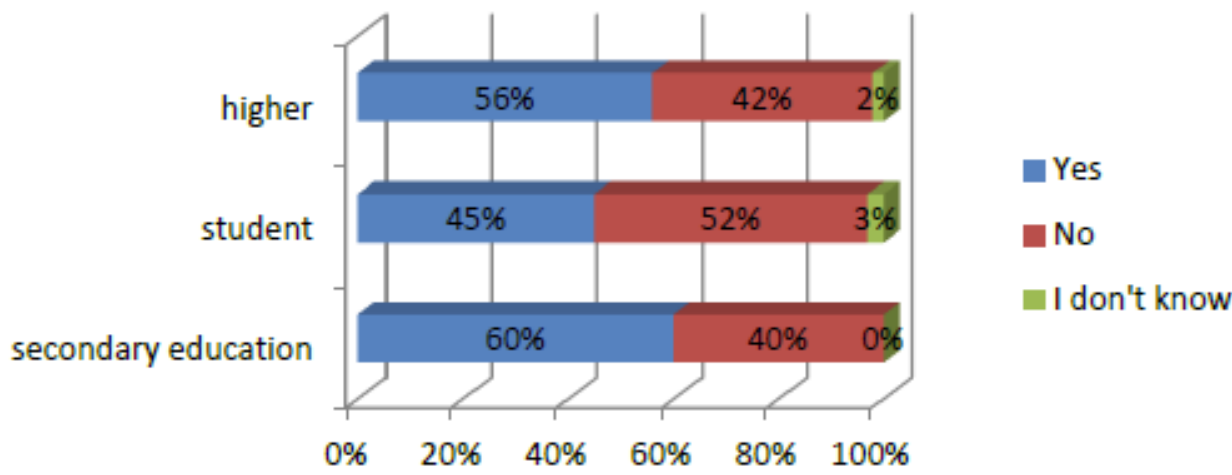

Source: Own findings, based on Research Project NI 1-4/2014 (UNWE, 2018).

Respondents declare the highest willingness to purchase the following products by companies certified under EMAS or ISO14001 - food, cleaning materials, textiles, furniture, building materials, and transport services.

\section{Summarized conclusions and discussion about the prospects for the development of environmental standards in Bulgaria}

Based on the analysis the following conclusions about the prospects for the development of environmental standards in Bulgaria are drawn:

- Issues related to environmental protection executed by organizations become more topical and become an integral part of the strategy for corporate social and environmental responsibility of these companies, leading to an increase in the number of companies registered under EMAS and ISO14001.

- Main reasons for the low level of distribution of environmental standards in country are the poor awareness by part of the companies; the poor advertising and promotion campaigns or lack of any advertising about the benefits of its implementation; the slow and bureaucratic procedure for its implementation; 
the large volume of required documentation; the complexity of implementing the standards.

- Almost three quarters of respondents expect in the coming years the importance of environmental standards to rise due to increased environmental problems and the need for taking measures which will alleviate their control. This will lead to improved legislation in this area and better organization and distribution of control activities between the various institutional partners. Implementation of standards will reduce the negative eco-influence of the companies, will expand the market opportunities and will strengthen the competitiveness of these companies according to the opinion of majority of the respondents.

- Environmental standards create better working environment and motivation among employees at all levels. Another important benefit cited by respondents is improved image of company to all stakeholders.

- Positive impact on extending and increasing the number of companies registered under EMAS and ISO14001 in Bulgaria have the mandatory requirements for the presence of such registration for companies wishing to participate in government tender contracts for the supply of various goods and services, and the need to meet the increased regulatory requirements in the field of environmental protection.

- Strengthening the role of corporate image and reputation in the process of making a selection of goods and services by consumers, the need for more efficient use of resources and the necessity to reduce the negative environmental impact of the activities of businesses leads to increased opportunities for the wider and faster distribution in Bulgaria of the environmental managements systems.

- There is a positive attitude towards implementation of standards for environmentally responsible behaviour by firms by end users who are also the workers in those companies, which is the basis for a wider dissemination of environmental standards in Bulgaria.

- Increased environmental awareness, the growing problems of environmental pollution have caused respondents to welcome environmentally responsible behaviour of companies and their purchases are influenced by the fact that the goods or services are produced by company applying eco-standards. This fact motivates the companies to implement eco-standards.

- The desire for a more efficient use of resources motivates consumers to be 
more critical to the used by the companies' technologies and to be more active in persuading the organizations to implement practices aimed at reduction of consumption of electricity, water and heat.

It can be concluded that there are opportunities for a wider dissemination of environmental standards in Bulgaria, which can be amplified by a more active state policy in this area; by providing fiscal and institutional incentives for companies implementing these standards; by strengthening the institutional support through establishing centres for provision of competent and professional advice and consultations of the business in terms of the different options to improve their ecological presentation; through information campaigns aimed at consumers and producers through which they are informed about the various environmental tools, the benefits of their implementation and their importance for environmental protection.

\section{References}

1. BIC (2003). Manual for implementation of ISO 14001. Bulgarian Industrial Chamber(BIC), Center "Clean Industry", Systems for environmental management in industrial enterprises, Sofia, Bulgaria.

2. Clausen, J., Keil, M., Jungwirth, M. (2002). The state of EMAS in the EU: Eco-Management as a tool for sustainable development. In: Literature Study in the European conference - The EU Eco-Management and Audit Scheme-Benefits and challenges of EMAS II, Institute for Ecological Economy Research, Berlin Germany, vol. 26, p. 27.

3. Dineva, V. (2019). Examination of the importance and influence of control environment on the innovative environment. In: Research and Innovation, Yunona Publishing, NY, USA, pp. 148-152.

4. EC (2006). EMAS: Toolkit for small organisations. European Commission (EC), Brussels, Belgium, available at: https://ec.europa.eu/environment/archives/emas/ toolkit/index.htm

5. EC (2009). Regulation no. 1221/2009 of the European Parliament and of the Council on the voluntary participation by organisations in a Community ecomanagement and audit scheme (EMAS). European Commission (EC), Brussels, Belgium.

6. EEC (1993). Council Regulation (EEC) no. $1836 / 93$ of 29 th June 1993 allowing voluntary participation by companies in the industrial sector in a Community ecomanagement and audit scheme (EMAS). Official Journal L, 168(10),07.

7. EPA (2005). Environmental Protection Act. State Gazette, no. 55.

8. Ilieva, L. (1999). Environmental Management. Tilia OOD, Sofia, Bulgaria. 
9. IPCC (2001). Climate Change 2001: The Scientific Basis. IPCC $3^{\text {rd }}$ Assessment Report, Intergovernmental Panel on Climate Change(IPCC), Geneva, Switzerland.

10.Iraldo, F., Kahlenborn, W., Rubik, F., Hertin, J., Nielsen, B. (2005). EVER: Evaluation of EMAS and Eco-label for Their Revision. Project report, IEFE University Bocconi, Milan, Italy.

11.Ivanova, D., Haradinova, A., Vasileva, E. (2016). Environmental performance of companies with environmental management systems in Bulgaria. Calitatea: Quality Access to Success, 17(152):61-66.

12.Maijala, A., Pohjola, T. (2006). Web-Based Environmental Management Systems for SMEs: Enhancing the Diffusion of Environmental Management in the Transportation Sector. In: Sustainability Accounting and Reporting, Springer, Dordrecht, the Netherland, pp. 655-677.

13.Matuszak Flejszman, A., Szyszka, B., Jóhannsdóttir, L. (2019). Effectiveness of EMAS: A case study of Polish organisations registered under EMAS. Environmental Impact Assessment Review, 74:86-94.

14.Miteva, A. (2017). Opportunities for expanding the application of environmental management and audit scheme in Bulgaria. Bulgarian Journal of Agricultural Science, 23(6):915-921.

15.Peicheva, M. (2018). A model for social audit of corporate social responsibility. Journal SEPIKE, 20(20):158-162.

16.Peicheva, M., Kraeva Miteva, A., Harizanova, H. (2017). Study of the Social Audit and Standards for Social and Environmental Responsibility-Case Study of Bulgaria. Economic Alternatives, 3:449-474.

17.Sahin, S., Narayanan, B., Aleksandrova, S. (2019). Top Down and Bottomup Approaches to Climate Change Adaptation in Bulgaria. In: 22 ${ }^{\text {nd }}$ Annual Conference on Global Economic Analysis, proceedings, Ministry of Environment and Water, Warsaw, Poland.

18.Stoyanova, Z. (2017). Impact of climate change related policies on the sector of green jobs. Trakia Journal of Sciences, 15(4):375-380.

19.UNEP- IETC (2000). Application of Environmental Management Systems Principles to Urban Management UNEP-IETC. Training Manual, United Nations Environmental Program - International Environment Technology Centre (UNEPIETC), Osaka, Japan.

20.UNWE (2018). Research of the needs to conduct social audit and implementation of standards of social and environmental responsibility in Bulgaria. Report, Scientific project NI 1-4/2014 (leaded by Peicheva, M.), University of National and World Economy (UNWE), Sofia, Bulgaria. 